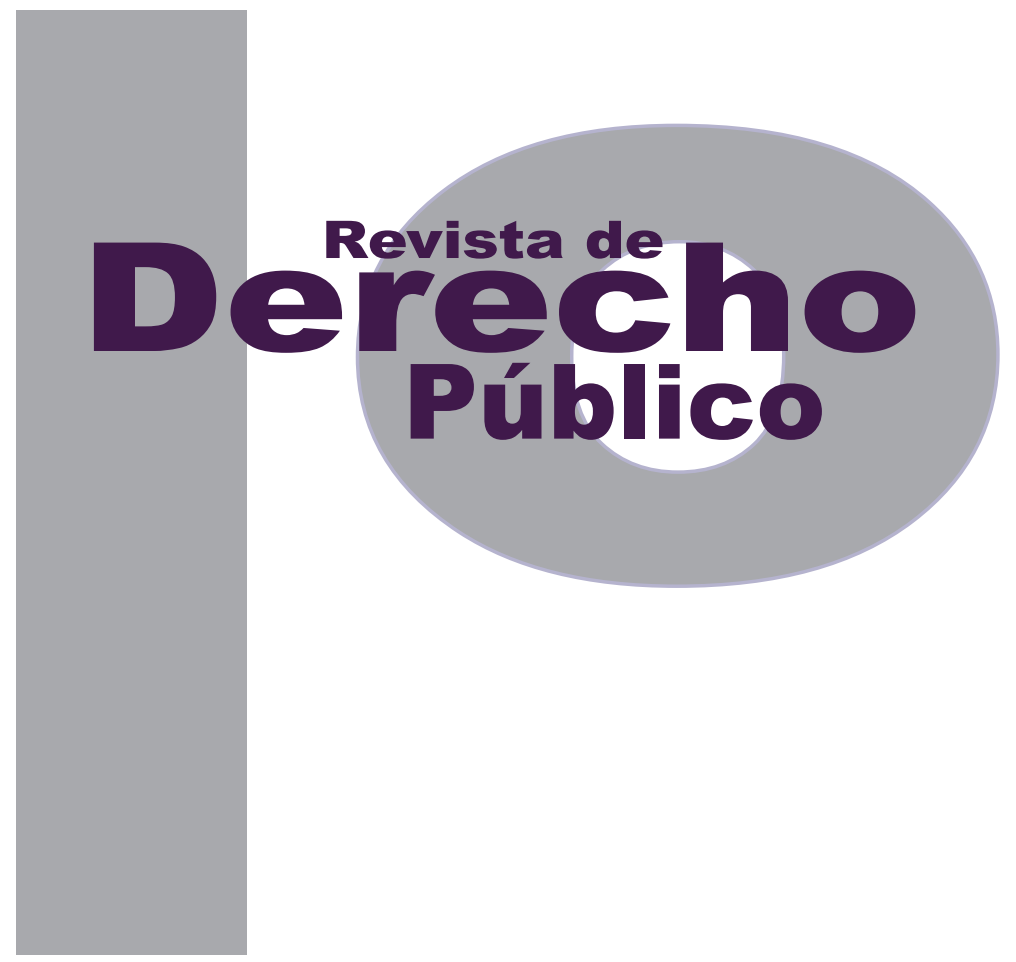

FACILIDADES PARA EL DESEMPEÑO DE LOS REPRESENTANTES DE LAS ORGANIZACIONES DE EMPLEADOS PÚBLICOS Y DE LOS REPRESENTANTES SINDICALES DE LOS TRABAJADORES EN LA NEGOCIACIÓN COLECTIVA

Katherine Müller RUEdA

Carlos fernando Morantes Franco

Artículo corto

DOI: http://dx.doi.org/10.15425/redepub.34.2015.29

Universidad de los Andes

Facultad de Derecho

Revista de Derecho Público N. ${ }^{\circ} 34$

Enero - Junio de 2015. ISSN 1909-7778 


\title{
Facilidades para el desempeño de los representantes de las organizaciones de empleados públicos y de los representantes sindicales de los trabajadores en la negociación colectiva
}

\section{Resumen}

El objetivo principal de este artículo de reflexión es analizar y comparar las facilidades establecidas para los representantes sindicales del sector público y privado en el ámbito tanto interno como internacional y establecer posibles diferencias o similitudes en su tratamiento jurídico. En aplicación de la investigación jurídica doctrinal, mediante el método analítico, se deduce la existencia de similares prerrogativas normativas en el ámbito interno para los representantes de los trabajadores de la empresa y para los representantes sindicales de los empleados públicos; no obstante lo anterior, se observa que dicha normatividad aún es insuficiente, y que Colombia requiere aprovechar la tendencia actual de reglamentación de los convenios internacionales para consagrar expresamente las facilidades de los representantes sindicales tanto del sector público como del sector privado.

Palabras clave: garantías sindicales, empleados públicos, negociación colectiva, sindicalistas.

\section{Facilities for the performance of the representatives of public employees' organizations and of the representatives of trade unions to the collective bargaining}

\begin{abstract}
This study is a reflection paper whose main objective is to analyze and compare the established facilities for union representatives from the public and private sector, both domestically and internationally, in order to settle posible differences or similarities in its legal treatment. Pursuant to the doctrinal legal research by the analytical method, we conclude the existence of similar regulation prerogatives for union workers's representatives and for public employees' representatives in the domestic context; notwithstanding the foregoing we observe that such regulation is still insufficient and that Colombia requires to seize the current regulation trend of international conventions regimentation to explicitly enshrine union representatives facilities', both public and private sector.
\end{abstract}

Keywords: union guarantees, public employees, collective bargaining, union.

\section{Facilidades para o desempenho dos representantes das organizações de empregados públi- cos e dos representantes sindicais dos trabalhadores na negociação coletiva}

\section{Resumo}

O objetivo principal deste artigo de reflexão é analisar e comparar as facilidades estabelecidas para os representantes sindicais do setor público e privado no âmbito tanto interno quanto internacional e estabelecer possíveis diferenças ou similitudes em seu tratamento jurídico. Em aplicação da pesquisa jurídica doutrinal, mediante o método analítico, se deduz a existência de similares prerrogativas normativas no âmbito interno para os representantes dos trabalhadores da empresa e para os representantes sindicais dos empregados públicos; não obstante o anterior, se observa que dita normatividade ainda é insuficiente, e que a Colômbia requer aproveitar a tendência atual de regulamentação dos convênios internacionais para consagrar expressamente as facilidades dos representantes sindicais tanto do setor público quanto do setor privado.

Palavras-chave: garantias sindicais, empregados públicos, negociação coletiva, sindicalistas. 


\title{
Facilidades para el desempeño de los representantes de las organizaciones de empleados públicos y de los representantes sindicales de los trabajadores en la negociación colectiva*
}

\author{
Katherine Müller Rueda** \\ Carlos Fernando Morantes Franco**
}

\section{SUMARIO}

Introducción - I. ALGUNAS PRECISIONES DEL DERECHO A LA NEGOCIACIÓN COLECTIVA Y EL DERECHO DE ASOCIACIÓN - II. BREVE RECUENTO DEL DERECHO DE NEGOCIACIÓN COLECTIVA PARA LOS EMPLEADOS PÚBLICOS EN COLOMBIA - III. FACILIDADES RECONOCIDAS PARA LOS REPRESENTANTES SINDICALES EN LAS NORMAS INTERNACIONALES DEL TRABAJO - A. Facilidades establecidas para los representantes sindicales del sector privado en el ámbito internacional - B. Facilidades establecidas para los representantes sindicales de los empleados públicos en el ámbito internacional - C. Fuerza vinculante de la Recomendación 159 y 143 de la Conferencia Internacional del Trabajo - IV. FACILIDADES RECONOCIDAS EXPRESAMENTE PARA LOS REPRESENTANTES SINDICALES EN LA NORMATIVIDAD INTERNA COLOMBIANA - A. Facilidades establecidas para los representantes sindicales de los empleados públicos en el ámbito interno - B. Facilidades establecidas para los representantes sindicales de los trabajadores de la empresa en el ámbito interno - C. Cuadro comparativo - V. CONCLUSIONES - Referencias.

\footnotetext{
* Cómo citar este artículo: Müller Rueda, K. y Morantes Franco, C. (Junio, 2015). Facilidades para el desempeño de los representantes de las organizaciones de empleados públicos y de los representantes sindicales de los trabajadores en la negociación colectiva. Revista de Derecho Público, 34 Universidad de los Andes (Colombia).

** Investigadora del Centro de Investigaciones Jurídicas y Sociojurídicas de la Universidad Libre Seccional Socorro. Correo: katherine.muller.rueda@ gmail.com

*** Docente investigador Universidad Libre Seccional Socorro. Candidato a Magíster en Derecho del Trabajo de la Universidad Externado de Colombia Correo: carlosf.morantesfranco.abogado@gmail.com
} 
Introducción

El presente estudio tiene por objeto determinar las facilidades establecidas expresamente para el desempeño de los representantes sindicales de empleados públicos en la legislación colombiana, a la luz del Convenio 151 sobre las relaciones de trabajo en la administración pública, de la Organización Internacional del Trabajo (отт), y la respectiva Recomendación 159. Dichas facilidades serán comparadas con las medidas sugeridas en la Recomendación 143 sobre los representantes de los trabajadores del sector privado, con la finalidad de analizar la eficacia de una y otra normatividad en el ámbito interno.

A raíz del Convenio 151, y producto de las reivindicaciones sociales logradas por los líderes sindicales de las federaciones y confederaciones nacionales e internacionales, se promulgaron los decretos 1092 de 2012 y 160 de 2014 que otorgaron a los empleados públicos el derecho de presentar pliegos de peticiones y realizar negociaciones colectivas, con el fin de evitar cualquier forma de discriminación frente a los trabajadores del sector privado. En igual sentido, la presentación del Proyecto de Ley 177 de 2014, por medio del cual se ratifica el Convenio 135 de la oit sobre los representantes de los trabajadores, es un punto de interés que merece ser estudiado, dada su actualidad e implicaciones. Tales hechos evidenciaron la necesidad de este estudio sobre la reciente normatividad, teniendo en cuenta que aún se encuentra en proceso de socialización con las partes interesadas, labor en la que intervienen la oाt, el Ministerio del Trabajo, la Procuraduría General de la Nación, el Departamento Administrativo de la Función Pública y las centrales y federaciones sindicales, con el objetivo de lograr la mayor eficacia en el proceso de negociación colectiva del sector público.

El estudio de las facilidades concedidas tanto por las normas internacionales del trabajo como por la normatividad interna para el desempeño de los representantes sindicales del sector público, cobra vital importancia para el desarrollo de los derechos a la libertad sindical y a la negociación colectiva, toda vez que estas se erigen en elementos de garantía tendientes a materializar los derechos reconocidos en la Declaración Universal de Derechos Humanos y en el Pacto Internacional de Derechos Civiles y Políticos (Conferencia Internacional del Trabajo, 2013). Por ende, analizar cómo un Estado miembro que ha ratificado los convenios 87,98 , 151 y 154 de la oіт refleja en su normatividad el respeto y desarrollo de los principios allí consignados, mediante la consagración expresa de facilidades para los representantes sindicales, constituye un punto de partida para evaluar la eficacia material de los compromisos internacionales adquiridos.

La pregunta objeto de investigación que se pretende resolver es: ¿establece la normatividad colombiana facilidades para los representantes de los empleados públicos de conformidad con lo señalado por el Convenio 151 y la Recomendación 159 de la oır?

Para responder dicho interrogante se realiza, como primera medida, un breve recuento del 
desarrollo que ha tenido en Colombia el derecho a la negociación colectiva de los empleados públicos; posteriormente, se analizan las facilidades de los representantes de los empleados de la administración pública y los representantes de los trabajadores del sector privado para el desempeño de las funciones consagradas en los instrumentos internacionales, así como la fuerza vinculante de las recomendaciones 159 y 143; finalmente, se determinan las disposiciones internas que expresamente reconocen dichas facilidades para los trabajadores tanto del sector privado como del sector público. Producto de este estudio se presenta un cuadro comparativo que expone las diferencias y similitudes halladas.

\section{ALGUNAS PRECISIONES DEL DERECHO A LA NEGOCIACIÓN COLECTIVA Y EL DERECHO DE ASOCIACIÓN}

El derecho a la negociación colectiva ha tenido un desarrollo prolífico en las normas internacionales y nacionales; así mismo, inicialmente su definición fue restrictiva en relación con los empleados públicos; posteriormente, con el desarrollo de los instrumentos internacionales fue alcanzando una mayor amplitud en orden al reconocimiento de este derecho fundamental a los antes exceptuados.

Sin embargo, la negociación colectiva debe ser entendida, en forma amplia, como el medio o instrumento de concertación para alcanzar un resultado concreto: bien sea el acuerdo, para
Ios empleados públicos, o la convención colectiva de trabajo, para los trabajadores oficiales y privados. Uno y otro constituyen el fin, la meta, el producto de un proceso de negociación cuyo origen deriva indiscutiblemente del derecho humano de asociación sindical.

El derecho de asociación sindical es la piedra angular del derecho colectivo del trabajo, su importancia tiene eco en las normas internacionales que han establecido este derecho como su estandarte, por ejemplo, al incluirlo como norma constitucional de la Organización de Estados Americanos (oEA) y de olt, así como al incorporarlo en la Carta Americana.

En relación con el derecho de asociación sindical, la jurisprudencia del máximo tribunal constitucional de Colombia ha identificado tres dimensiones dentro de las cuales se ejerce su marco de acción:

(i). Dimensión individual: Consiste en la posibilidad que tiene cada persona de decidir si se afilia, si se retira o si permanece dentro de la organización, sin injerencia alguna o presiones externas, ni por parte del empleador ni incluso del mismo sindicato. (ii). Dimensión colectiva: En virtud de la cual los trabajadores organizados, pueden autogobernarse y decidir de manera independiente el destino de su organización sin admitir injerencia externa, especialmente del empleador. (iii). Dimensión instrumental: Según la cual el derecho de asociación es el medio para que los trabajadores puedan lograr la consecución de algunos fines, especialmente el mejoramiento de sus condiciones laborales (CConst., T-619/2013, J. Palacio). 
Así las cosas, el derecho de asociación sindical se expresa principalmente a través del derecho a la libertad de asociación sindical y el derecho a la negociación colectiva, aspectos estos cuya eficacia deriva fundamentalmente de las garantías otorgadas a las organizaciones de trabajadores para mejorar sus condiciones laborales.

El derecho a la libertad de asociación consagrado constitucionalmente en el artículo 38 Superior, preludio del derecho de asociación sindical (art. 39 C.P.), constituye una de las máximas expresiones del Estado social de derecho, que permite a los trabajadores ejercer su facultad de autodeterminación y, entre otras, designar a sus representantes libremente sin influencias externas de ninguna clase. A su vez, el derecho a la negociación colectiva constituye el medio para alcanzar, como antes se dijo, un acuerdo o convención colectiva que permita establecer de manera bilateral las condiciones que regirán las relaciones de trabajo.

Los anteriores derechos de contenido teórico amplio están llamados, de conformidad con lo señalado por la Carta Política, a ser aplicados en la práctica, es decir, a tener eficacia material. Por lo tanto, las facilidades otorgadas a los representantes sindicales de los trabajadores y a los representantes de las organizaciones de empleados públicos se erigen en garantía para lograr la materialización de los derechos antes mencionados.

Un Estado que respete y aplique las facilidades establecidas para los representantes sindicales en los instrumentos internacionales será un Es- tado en continuo desarrollo y ejercicio del derecho humano de asociación sindical.

\section{BREVE RECUENTO DEL DERECHO DE NEGOCIACIÓN COLECTIVA PARA LOS EMPLEADOS PÚBLICOS EN COLOMBIA}

El reconocimiento del derecho a la negociación colectiva de los empleados públicos ha significado, en Colombia, una lucha constante para su reivindicación y posterior ejercicio y goce.

En vigencia de la Constitución Nacional de 1886 y el Código Sustantivo del Trabajo de 1950, se proscribía a los empleados públicos de la posibilidad de presentar pliegos de peticiones, así como también del derecho a la negociación colectiva; situación que generó una crisis en relación con sus derechos, evidenciada en los pronunciamientos de la Misión Chenery.

En efecto, dicha misión afirmó las notables diferencias que se observaban entre los empleados del sector público y los trabajadores del sector privado, en los siguientes términos:

Los salarios medios de los trabajadores del sector público se han mantenido relativamente estancados a largo plazo, incluso con una ligera tendencia al deterioro. Por el contrario, los salarios promedio del sector privado en zonas urbanas y rurales han experimentado a largo plazo incremento visible (López, 1986, pág. 170).

Las diferencias anotadas por la Misión Chenery demostraban la precaria situación de los derechos de los empleados públicos y la necesidad 
de acuerdos en relación con sus condiciones de empleo; no obstante, las disposiciones legales entonces vigentes se erigían en una barrera para la concertación con el Gobierno. Pese a lo anterior, los pronunciamientos de la misión no resultaron en desueta teoría, pues poco tiempo después la inconformidad de dichos empleados vino a materializarse en fuertes paros que trajeron como consecuencia las negociaciones por vía de hecho. Ejemplo de ello lo constituye el paro de jueces, maestros, trabajadores de obras públicas, agricultura y contraloría realizado en el año 1965, y el cese de actividades en la Flota Mercante Grancolombiana, en el Servicio Nacional de Aprendizaje (SENA) y en el magisterio, en el año 1971 (Guarnizo, 2014). Sin embargo, ninguno de los acuerdos a los que llegaron estos sectores abrió la posibilidad de negociaciones colectivas con los empleados públicos.

Más tarde, el advenimiento de la Constitución Política de 1991 constituyó un avance en la lucha para la protección de los derechos laborales, las libertades sindicales y la negociación colectiva, a pesar de que solo reconoció la facultad de dichas negociaciones a los trabajadores particulares y oficiales, pues la libertad de configuración legislativa consagrada en el artículo 55 Superior le otorgó al Congreso de la República la facultad para señalar excepciones.

Así las cosas, los empleados públicos tenían el derecho a constituir y afiliarse a organizaciones sindicales, por disponerlo así el artículo 414 del Código Sustantivo del Trabajo (CST), pero no podían presentar pliegos de peticiones, ni realizar convenciones colectivas por virtud del artículo
416 ibídem, solo presentar memoriales respetuosos, lo cual constituía una mera reiteración del derecho fundamental al derecho petición. A este contexto normativo interno se le sumaba el criterio establecido en el Convenio 98 sobre el derecho de sindicación y negociación colectiva de la oıт, ratificado por la Ley 27 de 1976, el cual excluyó de su ámbito de aplicación a los funcionarios públicos al servicio del Estado.

En efecto, tal como lo comenta Villegas (2014), la denegación del derecho de negociación colectiva por virtud de lo establecido en el artículo 414 del cst constituyó uno de los mayores errores de interpretación, al confundir el derecho a la negociación colectiva con uno de sus resultados: la convención colectiva de trabajo. Por consiguiente, pese a que se alcanzó el reconocimiento del derecho de asociación sindical a los empleados públicos, se les sustrajo, con amañadas interpretaciones, de una de sus expresiones: el derecho a la negociación colectiva. Como Villegas (2014) afirma:

En Colombia, la República Liberal de Olaya Herrera, mediante la Ley $83 / 31$, art. $2^{\circ}$, inició el camino de reconocimiento de los sindicatos de empleados públicos. Luego, el Código Sustantivo del Trabajo de 1950, expedido por el decreto de estado de sitio del gobierno conservador, después del asesinato de Gaitán, en plena época de la Violencia, aunque decía reconocer el derecho de sindicación de los empleados públicos, simultáneamente lo negaba, al excluir del fuero sindical a sus directivos sindicales -CST, art. 409, num. $1^{\circ}-$, negarles el derecho al pliego y a la negociación colectiva -llamada contratación o convención-, pues real y co- 
rrectivamente, el cst los postraba al reducirlos mediante "el otorgamiento" del derecho de petición llamado "memoriales respetuosos" -art. 414.4- (pág. 80).

Sin embargo, la Conferencia Internacional del Trabajo, consciente de la exclusión de ciertas categorías de empleados públicos, y con la finalidad de evitar cualquier forma de discriminación hacia ellos, adoptó el Convenio 151 sobre las relaciones de trabajo en la administración pública, el cual fue ratificado por Colombia mediante la Ley 411 de 1997. Dicho convenio otorgó el derecho a la negociación colectiva a los empleados públicos, asignándole excepcionalmente al legislador la potestad de establecer hasta qué punto dicha garantía sería otorgada a "Ios empleados de alto nivel que, por sus funciones se considera normalmente que poseen poder decisorio o desempeñan cargos directivos o a los empleados cuyas obligaciones son de naturaleza altamente confidencial" (Convenio 151, art. 1.2.).

A pesar de los esfuerzos de la olт por extender el derecho de negociación colectiva a los empleados públicos, las sentencias de la Corte Constitucional y la Corte Suprema de Justicia siguieron retringiéndolo. La Corte Constitucional, por ejemplo, en la sentencia C-377 de 1998 afirmó:

La Corte debe condicionar el alcance de los artículos $7^{\circ}$ y $8^{\circ}$ del Convenio bajo revisión [Convenio 151] en relación con los empleados públicos, por cuanto esas normas autorizan a tomar en cuenta las especificidades de las situaciones nacionales. Así, el artículo $7^{\circ}$ no consagra un derecho de negociación colectiva pleno para todos los servidores públicos.

Según Guarnizo (2014), en consonancia con los pronunciamientos de las Cortes, el Decreto 535 de 2009 proferido por el entonces presidente Álvaro Uribe Vélez reglamentó el artículo 416 del cst, prohibiendo con ello el derecho a la negociación colectiva de los empleados públicos y autorizándolos solo a realizar peticiones respetuosas y no pliegos. No obstante, en el año 2010 los dirigentes sindicales de las federaciones estatales, en el mandato del presidente Juan Manuel Santos Calderón, radicaron un pliego unificado que no fue atendido, situación que conllevó a que la Federación Nacional de Trabajadores al Servicio del Estado (FENALTRA$\mathrm{SE})$, la Federación Colombiana de Educadores (FECODE), la Unión de Trabajadores del Estado y los Servicios Públicos (UTRADEC), la Federación Unión Nacional de Trabajadores del Estado y los Servicios Públicos (UNETE), la Federación Nacional de Servidores Públicos (FENASER), la Federación Colombiana de Trabajadores y Servidores Públicos (FECOTRASERVIPúBLICOS) y las confederaciones Central Unitaria de Trabajadores (cUT), Confederación General de Trabajo (CGT), Confederacion de Trabajadores de Colombia (стс), la Internacional de Servicios Públicos (ISP), y el Gobierno Nacional conformaran una mesa sectorial y llevaran a cabo una reglamentación que reconociera el Convenio 151. De dicho acuerdo nació el Decreto 1092 de 2012 que concedió por primera vez y de manera expresa el derecho de los empleados públicos a la negociación colectiva, salvo ciertas excepciones. 
Posteriormente, el 7 febrero de 2013, los empleados públicos presentaron un pliego unificado de peticiones al Gobierno, cuya negociación conllevó acordar disposiciones para mejorar las falencias del Decreto 1092. El 5 de febrero del 2014 fue proferido el Decreto 160 que amplió los asuntos objeto de negociación colectiva, concretó las etapas de la negociación y vinculó de manera expresa el Convenio 151.

En definitiva, el derecho a la negociación colectiva por parte de los empleados públicos es resultado de un proceso de más de quince años (1997-2012) de luchas y reivindicaciones impulsadas constantemente por los sindicatos. Su importancia radica en que constituye un eje fundamental en la evolución hacia la eficiencia en la prestación del servicio público, el logro de relaciones de trabajo armoniosas y la creación de condiciones de trabajo decentes (Conferencia Internacional del Trabajo, 2013).

El estudio de las facilidades establecidas para el desempeño de los representantes sindicales, como concreción de los derechos alcanzados tras años de lucha, se abordará en los siguientes capítulos a fin de analizar si la legislación nacional, en relación con los empleados públicos, ha avanzado a la par con las normas establecidas para los trabajadores del sector privado.

\section{FACILIDADES RECONOCIDAS A LOS REPRESENTANTES SINDICALES EN LAS NORMAS INTERNACIONALES DEL TRABAJO}

Las facilidades otorgadas por los instrumentos internacionales a los representantes sindicales, para que puedan desempeñar con eficacia sus funciones, son una consecuencia lógica de los derechos de asociación sindical y negociación colectiva, al tiempo que materializan los derechos señalados en dichos instrumentos para los trabajadores, cualquiera sea su clase.

Es importante anotar que las expresiones "representantes de los trabajadores" y "representantes de las organizaciones de empleados públicos" serán entendidas en su amplia acepción, de conformidad con lo señalado por los convenios 135 (artículo 3) y 154 (artículo 3 parágrafo 1). Comprenden, por tanto, a los representantes sindicales electos por los trabajadores de la empresa, cualquiera sea su clase, así como a los elegidos por los sindicatos o por los afiliados a ellos o por las organizaciones de empleados públicos.

Igualmente, es relevante señalar que la adopción de facilidades por parte de los instrumentos internacionales para los representantes de las organizaciones de empleados públicos se dio de manera gradual y con posterioridad a los trabajadores de la empresa. El análisis que se hace a continuación atiende dicho orden. 


\section{A. Facilidades establecidas para los representantes sindicales del sector privado en el ámbito internacional}

El Convenio 87 de la oाт establece en su artículo 11 la obligación que tienen los Estados Miembros de "adoptar las medidas necesarias y apropiadas para garantizar a los trabajadores y a los empleadores el libre ejercicio del derecho de sindicación". Esto implica el deber de respetar, entre otros, la libertad de los trabajadores para elegir a sus representantes, así como también las funciones desempeñadas por estos últimos con la finalidad de cumplir con los objetivos de la organización sindical (oıт, 2006).

Por su parte, el Convenio 135 de la olt relativo a la protección y facilidades que deben otorgarse a los representantes de los trabajadores en la empresa, señala el derecho que les asiste a estos de disponer de facilidades que les permitan desempeñar sus funciones, sin perjudicar el normal y eficaz funcionamiento de la empresa. Al respecto, la Recomendación 143 se encarga de concretar con carácter no taxativo dichas facilidades, las cuales para efectos de este estudio se han catalogado en seis tipologías, a saber:

1. Permisos para actividades sindicales: implica la garantía para los representantes sindicales de disfrutar de tiempo libre para ejercer efectivamente sus funciones como tales, así como también para capacitarse sindicalmente, sin que dichos permisos signifiquen pérdida de salario. El deber de brindar permisos para la capacitación y el ejercicio de la labor sindical fortalece el respeto por las normas internacionales del trabajo, así como la eficacia y efectividad de los servicios.

2. Acceso a los lugares de trabajo: para el correcto ejercicio de la labor sindical es indispensable que los representantes puedan acceder a los lugares de trabajo de los afiliados, así no pertenezcan a la misma empresa o entidad de estos. Sobre este particular el Comité de Libertad Sindical de la oıt, afirmó:

Los gobiernos deben garantizar el acceso de los representantes sindicales a los lugares de trabajo, con el debido respeto del derecho de propiedad y de los derechos de la dirección de la empresa, de manera que los sindicatos puedan comunicarse con los trabajadores para que puedan informarles de los beneficios que se deriven de la afiliación sindical (2006, pág. 240).

3. Comunicación con la dirección: es la garantía de que gozan los representantes sindicales para entrar en comunicación directa y sin dilaciones injustificadas, con los directivos de la empresa o los representantes autorizados por esta para tomar decisiones.

4. Cobro de cuotas sindicales: los representantes podrán realizar el cobro de cuotas sindicales, siempre y cuando no exista otro mecanismo de recaudación, "lo que permite una gestión adecuada de las finanzas de las organizaciones" (Conferencia Internacional del Trabajo, 2013, pág. 49).

5. Distribuir información: implica permitirles a los representantes distribuir folletos, avisos o 
cualquier otra clase de información relacionada con la actividad sindical.

6. Facilidades materiales e información: la Comisión de Libertad Sindical resume dichas facilidades en "disponibilidad de un local, con o sin mobiliario, material de oficina, un lugar de almacenamiento, un lugar de colocación de avisos y medios de transporte o el pago de los gastos de viaje" (оıт, 2006, pág. 50). En este aspecto es necesario recordar que la posibilidad de reunirse en lugares de trabajo, fuera o no de los horarios de labor, no requiere autorización previa por parte del empleador por ser de la naturaleza propia del derecho de libertad sindical y de asociación.

\section{B. Facilidades establecidas para los representantes sindicales de los empleados públicos en el ámbito internacional}

Pese a que el reconocimiento de facilidades para los representantes de las organizaciones sindicales de empleados públicos en los instrumentos internacionales fue posterior al de los trabajadores del sector privado, la normatividad aplicable es la misma en virtud de la remisión efectuada en el párrafo 4 de la Recomendación 159.

El Convenio 151 de la oाt establece en el artículo $6^{\circ}$ la obligación de reconocer a los representantes de las organizaciones de empleados públicos facilidades necesarias para desempeñar sus funciones. La Recomendación 159, con el ánimo de desarrollar estas facilidades, sugiere que para definir tanto su naturaleza como su alcance se tengan en cuenta los lineamientos establecidos en la Recomendación 143, anteriormente analizada. De esta manera, dicha recomendación equipara la normatividad para estas dos clases de trabajadores, en punto a las facilidades otorgadas a sus representantes sindicales.

Teniendo en cuenta que en el ámbito internacional las normas sobre las facilidades para el ejercicio de las funciones de los representantes sindicales son las mismas, conviene estudiar la fuerza vinculante de las recomendaciones que señalan explícitamente estas facilidades en el contexto colombiano, a fin de analizar si estas sirven de criterio orientador como fuente interpretativa de la actividad judicial.

\section{Fuerza vinculante de las recomendaciones 159 y 143 de la Conferencia Internacional del Trabajo}

Mucho se ha dicho respecto de la fuerza vinculante de las recomendaciones proferidas por la Conferencia Internacional del Trabajo (CIT), en el sentido de no atribuirles la obligatoriedad de un tratado o convenio internacional ratificado, pero sí el orientar la actuación de las autoridades nacionales como consecuencia de un convenio ratificado por el Estado (Conferencia Internacional del Trabajo, 2013; Ramírez, 2010).

Siguiendo los anteriores lineamientos, la Recomendación 159 por ser desarrollo del Convenio 151, ratificado por Colombia mediante la Ley 411 de 1997, sirve como criterio orientador de la actividad judicial o como fuente supletoria según el artículo 19 cst. No ocu- 
rre lo mismo con la Recomendación 143, en razón a que el Convenio 135 que ella desarrolla no ha sido ratificado por nuestro país, situación que le resta fuerza vinculante general.

Sin embargo, en relación con las facilidades concedidas a los representantes sindicales existe un aspecto que es importante analizar: al presentarse una remisión a la Recomendación 143 esta cobra la misma fuerza de la Recomendación 159, lo que implica que las medidas en ella señaladas deben ser observadas por las autoridades nacionales al orientar sus políticas.

En otros términos, la Recomendación 143, en lo que atañe a las "facilidades que habrán de otorgarse a los representantes de los trabajadores" reviste el mismo carácter de la Recomendación 159 por expresa remisión, razón por la cual aunque no es de obligatorio cumplimiento sí orienta la actividad judicial o sirve de norma supletoria para la aplicación del Convenio 151 o la normatividad nacional.

\section{FACILIDADES RECONOCIDAS EXPRESAMENTE PARA LOS REPRESENTANTES SINDICALES EN LA NORMATIVIDAD INTERNA COLOMBIANA}

Una vez expuestos los lineamientos de los instrumentos internacionales, es necesario analizar su reglamentación en la normatividad interna colombiana con el fin de evaluar su cumplimiento.

Conviene anotar que solo se analizarán las disposiciones legales, pues es la ley, entendida en sentido formal "el principal método de aplicación de los Convenios a nivel nacional" (Conferencia Internacional del Trabajo, 2013, pág. 41), la que reviste carácter vinculante y señala con abstracción suficiente los requisitos y condiciones mínimas para el respeto de los derechos.

Lo anterior no implica que dichas condiciones y requisitos mínimos no puedan ser ampliados por instrumentos como los acuerdos colectivos, las consultas, los fallos arbitrales o cualquier otro que permita determinarlas, dado que es absolutamente plausible que en virtud de arreglos se puedan llegar a establecer mayores facilidades y beneficios en este sentido.

El artículo 39 de la Constitución Política de Colombia constituye la principal directriz en lo que respecta a la protección del derecho de asociación y las facilidades para materializarlo tanto en lo concerniente a los empleados públicos como a los trabajadores privados.

En el análisis de las facilidades para unos y otros se emplearán como variables de comparación las seis tipologías señaladas en el capítulo anterior.

\section{A. Facilidades establecidas para los representantes sindicales de los empleados públicos en el ámbito interno}

1. Permisos para actividades sindicales: la legislación al respecto es prolífica, dispersa y evidencia el cumplimiento de las normas internacionales del trabajo. 
En primer término se encuentra el artículo 416 A del Cst, adicionado por el artículo 13 de la Ley 584 de 2000, que consagra el derecho de los empleados públicos a gozar de permisos sindicales, al tiempo que obliga al Gobierno a reglamentar el asunto. Siguiendo la orden señalada en este artículo, el Gobierno expidió el Decreto 2813 de 2000 el cual otorga la titularidad de dicha facilidad a "los comités ejecutivos, directivas y subdirectivas de confederaciones y federaciones, juntas directivas, subdirectivas y comités seccionales, comisiones legales o estatutarias de reclamos de los sindicatos" (art. 1). Igualmente estipula que la facilidad reconocida será otorgada sin pérdida de salarios y prestaciones, mediante acto administrativo del nominador o el funcionario delegado, previa solicitud del sindicato, en la cual señale el nombre del representante, el término del permiso y su finalidad.

A su vez, el Decreto 160 de 2014 reconoce en el artículo 15 el derecho al permiso sindical en los términos de la normatividad vigente, y en el artículo 16 señala la obligación de las entidades públicas de brindar capacitación en materia de negociación colectiva, lo que a su vez implica el deber del permiso sindical en materia de capacitación.

\section{Acceso a los lugares de trabajo: no se observa} norma expresa tendiente a garantizar el acceso de los representantes sindicales a los lugares de trabajo, sean o no empleados de la entidad.

3. Comunicación con la dirección: el artículo 415 del cst señala el deber de las autoridades de los empleados públicos de recibir a los repre- sentantes sindicales y atender oportunamente sus solicitudes. El Decreto 2813 de 2000, art. 3 párr. 2 indica el mismo deber respecto de las solicitudes de permisos sindicales. Lo anterior evidencia el cumplimiento de la normatividad internacional.

4. Cobro de cuotas sindicales: el Decreto 2264 de 2013 regula este aspecto, y establece para el empleador la obligación de deducir del salario de los afiliados la cuota sindical, y la de retener y entregar directamente a la organización sindical las cuotas federales y confederales que el sindicato afiliado esté obligado a pagar (art. 1 nums. a y b), así como las sumas de los empleados no afiliados que se beneficien de la convención colectiva, y las que estos autoricen voluntariamente (Ley 50, 1990, art. 68). El artículo 362, numerales $7^{\circ}$ y $8^{\circ}$ del cst, dispone la obligación de establecer en los estatutos del sindicato la cuantía, periodicidad y forma de pago de las cuotas ordinarias y el procedimiento para decretar y cobrar las cuotas extraordinarias. Lo anterior en cumplimiento de la normatividad internacional.

5. Distribuir información: no se observa norma expresa tendiente a garantizar este derecho de los representantes sindicales.

6. Facilidades materiales e información: el artículo 414 numeral $8^{\circ}$ del cst señala el derecho que les asiste a las organizaciones sindicales de empleados públicos de "adquirir a cualquier título y poseer los bienes inmuebles y muebles que se requieran para el ejercicio de sus actividades". Sin embargo, no existe ninguna disposición legal que consagre el deber de las autoridades 
públicas de disponer lugares de reunión para las organizaciones sindicales (con o sin mobiliario), material de oficina, espacio para colocación de avisos, ni el de brindar medios de transporte o viáticos para los representantes sindicales en el desempeño de sus funciones. En relación con este aspecto, el Ministerio de la Protección Social (concepto 216110, 2011) afirmó: “La norma laboral colectiva no consagra la obligación de otorgar viáticos, pues únicamente se refiere al derecho de disfrutar de tiempo libre necesario para las actividades sindicales sin pérdida de salario ni prestaciones u otras ventajas sociales". Así las cosas, la normatividad en este sentido es deficiente.

\section{B. Facilidades establecidas para los representantes sindicales de los trabajadores de la empresa en el ámbito interno}

1. Permisos para actividades sindicales: no se observa norma expresa que consagre el derecho que asiste a los representantes sindicales de los empleados particulares para obtener permisos que les permitan el desarrollo de sus funciones como tales.

2. Acceso a los lugares de trabajo: tampoco se encontró norma alguna tendiente a garantizar este derecho de los representantes sindicales, sean o no empleados de la empresa.

3. Comunicación con la dirección: el artículo 375 del cst establece con suficiencia el deber de los empleadores y las autoridades de atender no solo a los representantes sindicales, sino también a sus apoderados y voceros cuando estos actúen en cumplimiento de las funciones asignadas a los sindicatos. Dicha normatividad garantiza el cumplimiento de las directrices establecidas en los instrumentos internacionales en relación con la comunicación directa y sin dilaciones con las directivas de la empresa.

4. Cobro de cuotas sindicales: en este punto las normas aplicables a los representantes de los empleados públicos se extienden a los representantes sindicales de los trabajadores de la empresa. También es importante mencionar el artículo 400 del cst, por cuanto señala el deber del empleador de realizar la deducción de las cuotas sindicales ordinarias o extraordinarias de los salarios de sus empleados y la obligación de ponerlas a disposición del sindicato, previa presentación del acta autenticada de la asamblea sindical que las ha aprobado (cuando se trate de cuotas extraordinarias), o certificación firmada por el secretario y el fiscal del sindicato con indicación del valor y la nómina de los afiliados (cuando sean cuotas ordinarias). Para retener las cuotas sindicales de las federaciones, confederaciones y centrales se requerirá comunicación firmada por el presidente, el tesorero y el fiscal. Dichas retenciones cesarán cuando se manifieste por escrito la renuncia o expulsión del trabajador del sindicato. Lo anterior, acorde con la normatividad internacional al respecto.

5. Distribuir información: al igual que sucede con los empleados públicos, no se observa norma alguna tendiente a garantizar el derecho de los representantes sindicales de los trabajado- 
res particulares a distribuir información relacionada con la labor sindical.

6. Facilidades materiales e información: el artículo 373 numeral 10 del cst señala el derecho que les asiste a los sindicatos de las empresas para adquirir bienes muebles e inmuebles, en las mismas condiciones establecidas por el artículo 414 numeral 8 para las organizaciones sindicales de los empleados públicos. Tampoco en este caso se evidencia normatividad suficiente que garantice los derechos de los representantes sindicales a gozar de un espacio en el lugar de trabajo para realizar las reuniones sindicales, obtener viáticos cuando se tengan que desplazar para cumplir con sus funciones o disponer de carteleras en las empresas para colocar informaciones y anuncios.
La Corte Constitucional a través de sus pronunciamientos ha logrado extender dichas prerrogativas y llenar estos vacíos normativos mediante la interpretación de los derechos de la Carta Política. Así, en relación con el derecho de información que les asiste a los sindicatos ha señalado: "En la modalidad de fijación de afiches y carteles, debe la empresa establecer carteles o espacios aptos para el ejercicio eficaz de este derecho, para así armonizar su ejercicio con las regulaciones propias de un reglamento de trabajo" (CConst., T-434/11). Así, por vía de interpretación del texto Superior, la Corte Constitucional ha llegado a reconocer facilidades no establecidas en la normatividad colombiana.

\section{Cuadro comparativo}

\begin{tabular}{|c|c|c|c|c|c|}
\hline \multirow[b]{2}{*}{ TIPO DE FACILIDAD } & \multicolumn{2}{|c|}{ EMPLEADOS PÚBLICOS } & \multirow[b]{3}{*}{ 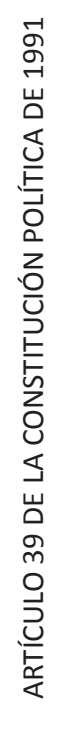 } & \multicolumn{2}{|c|}{ TRABAJADORES DE LA EMPRESA } \\
\hline & $\begin{array}{l}\text { Instrumento } \\
\text { internacional }\end{array}$ & Norma interna & & $\begin{array}{l}\text { Instrumento } \\
\text { internacional }\end{array}$ & $\begin{array}{l}\text { Norma } \\
\text { interna }\end{array}$ \\
\hline $\begin{array}{l}\text { Permisos para acti- } \\
\text { vidades sindicales }\end{array}$ & $\begin{array}{l}\text { Convenio } 87 \text { de } 1948 \\
\text { de la OIT, artículo } 11 . \\
\text { Convenio } 151 \text { de } 1978 \\
\text { de la OIT, artículo } 6^{\circ} \text {. } \\
\text { Numeral } 2.4 \text { de la } \\
\text { Recomendación } 159 \\
\text { de la CIT. } \\
\text { Numerales } 10 \text { y } 11.1- \\
\text { 11.2 de la Recomen- } \\
\text { dación } 143 \text { de la CIT. }\end{array}$ & $\begin{array}{l}\text { Artículo 416a CST, adi- } \\
\text { cionado por el artículo } \\
13 \text { de la Ley } 584 \text { de } \\
2000 . \\
\text { Decreto } 2813 \text { de } 2000 \text {. } \\
\text { Artículos } 15 \text { y } 16 \text { del } \\
\text { Decreto } 160 \text { de } 2014 \text {. }\end{array}$ & & $\begin{array}{l}\text { Convenio } 87 \text { de } 1948 \text { de } \\
\text { la OIT, artículo } 11 . \\
\text { Convenio } 135 \text { de } 1971 \\
\text { de la OIT, artículo } 2 .\end{array}$ & NO EXISTE \\
\hline
\end{tabular}




\begin{tabular}{|c|c|c|c|c|}
\hline \multirow[b]{2}{*}{ TIPO DE FACILIDAD } & \multicolumn{2}{|c|}{ EMPLEADOS PÚBLICOS } & \multicolumn{2}{|c|}{ TRABAJADORES DE LA EMPRESA } \\
\hline & $\begin{array}{l}\text { Instrumento } \\
\text { internacional }\end{array}$ & Norma interna & $\begin{array}{l}\text { Instrumento } \\
\text { internacional }\end{array}$ & $\begin{array}{l}\text { Norma } \\
\text { interna }\end{array}$ \\
\hline $\begin{array}{l}\text { Acceso a los luga- } \\
\text { res de trabajo }\end{array}$ & $\begin{array}{l}\text { Convenio } 87 \text { de } 1948 \\
\text { de la OIT, artículo } 11 . \\
\text { Convenio } 151 \text { de } 1978 \\
\text { de la OIT, artículo } 6^{\circ} . \\
\text { Numeral } 2.4 \text { de la } \\
\text { Recomendación } 159 \\
\text { de la CIT. } \\
\text { Numerales } 12 \text { y } 17 \\
\text { de la Recomendación } \\
143 \text { de la CIT. }\end{array}$ & NO EXISTE & $\begin{array}{l}\text { Convenio } 87 \text { de } 1948 \text { de } \\
\text { la OIT, artículo } 11 . \\
\text { Convenio } 135 \text { de } 1971 \\
\text { de la OIT, artículo } 2 . \\
\text { Numerales } 12 \text { y } 17 \text { de la } \\
\text { Recomendación } 143 \text { de } \\
\text { la CIT. }\end{array}$ & NO EXISTE \\
\hline $\begin{array}{l}\text { Comunicación con } \\
\text { la dirección }\end{array}$ & $\begin{array}{l}\text { Convenio } 87 \text { de } 1948 \\
\text { de la OIT, artículo } 11 . \\
\text { Convenio } 151 \text { de } 1978 \\
\text { de la OIT, artículo } 6^{\circ} \text {. } \\
\text { Numeral } 2.4 \text { de la } \\
\text { Recomendación } 159 \\
\text { de la CIT. } \\
\text { Numeral } 13 \text { de la Re- } \\
\text { comendación } 143 \text { de } \\
\text { la CIT. }\end{array}$ & $\begin{array}{l}\text { Artículo } 415 \text { del CST. } \\
\text { Artículo } 3^{\circ} \text { parágrafo } 2^{\circ} \\
\text { Decreto } 2813 \text { de } 2000 \text {. }\end{array}$ & $\begin{array}{l}\text { Convenio } 87 \text { de } 1948 \text { de } \\
\text { la OIT, artículo } 11 . \\
\text { Convenio } 135 \text { de } 1971 \\
\text { de la OIT, artículo } 2 . \\
\text { Numeral } 13 \text { de la Re- } \\
\text { comendación } 143 \text { de } \\
\text { la CIT. }\end{array}$ & $\begin{array}{l}\text { Artículo } \\
375 \text { del CST }\end{array}$ \\
\hline $\begin{array}{l}\text { Cobro de cuotas } \\
\text { sindicales }\end{array}$ & $\begin{array}{l}\text { Convenio } 87 \text { de } 1948 \\
\text { de la OIT, artículo } 11 . \\
\text { Convenio } 151 \text { de } 1978 \\
\text { de la OIT, artículo } 6^{\circ} \text {. } \\
\text { Numeral } 2.4 \text { de la } \\
\text { Recomendación } 159 \\
\text { de la CIT. } \\
\text { Numeral } 14 \text { de la Re- } \\
\text { comendación } 143 \text { de } \\
\text { la CIT. }\end{array}$ & $\begin{array}{l}\text { Artículo } 362, \text { numerales } \\
7^{\circ} \text { y } 8^{\circ} \text { del CST. } \\
\text { Artículo } 68 \text { de la Ley } 50 \\
\text { de } 1990 . \\
\text { Decreto } 2264 \text { de } 2013 .\end{array}$ & $\begin{array}{l}\text { Convenio } 87 \text { de } 1948 \text { de } \\
\text { la OIT, artículo } 11 . \\
\text { Convenio } 135 \text { de } 1971 \\
\text { de la OIT, artículo } 2 . \\
\text { Numeral } 14 \text { de la Re- } \\
\text { comendación } 143 \text { de } \\
\text { la CIT. }\end{array}$ & $\begin{array}{l}\text { Artículo } \\
362, \text { nume- } \\
\text { rales } 7^{\circ} \text { y } 8^{\circ} \\
\text { del CST. } \\
\text { Artículo } \\
400 \text { del CST. } \\
\text { Artículo } 68 \\
\text { de la Ley } 50 \\
\text { de } 1990 . \\
\text { Decreto } \\
2264 \text { de } \\
2013 .\end{array}$ \\
\hline
\end{tabular}




\begin{tabular}{|c|c|c|c|c|}
\hline \multirow[b]{2}{*}{ TIPO DE FACILIDAD } & \multicolumn{2}{|c|}{ EMPLEADOS PÚBLICOS } & \multicolumn{2}{|c|}{ TRABAJADORES DE LA EMPRESA } \\
\hline & $\begin{array}{l}\text { Instrumento } \\
\text { internacional }\end{array}$ & Norma interna & $\begin{array}{l}\text { Instrumento } \\
\text { internacional }\end{array}$ & $\begin{array}{l}\text { Norma } \\
\text { interna }\end{array}$ \\
\hline $\begin{array}{l}\text { Distribuir informa- } \\
\text { ción }\end{array}$ & $\begin{array}{l}\text { Convenio } 87 \text { de } 1948 \\
\text { de la OIT, artículo } 11 . \\
\text { Convenio } 151 \text { de } 1978 \\
\text { de la OIT, artículo } 6^{\circ} . \\
\text { Numeral } 2.4 \text { de la } \\
\text { Recomendación } 159 \\
\text { de la CIT. } \\
\text { Numeral } 15 \text { de la Re- } \\
\text { comendación } 143 \text { de } \\
\text { la OIT. }\end{array}$ & NO EXISTE & $\begin{array}{l}\text { Convenio } 87 \text { de } 1948 \text { de } \\
\text { la OIT, artículo } 11 . \\
\text { Convenio } 135 \text { de } 1971 \\
\text { de la OIT, artículo } 2 . \\
\text { Numeral } 15 \text { de la Re- } \\
\text { comendación } 143 \text { de } \\
\text { la OIT. }\end{array}$ & NO EXISTE \\
\hline $\begin{array}{l}\text { Facilidades mate- } \\
\text { riales e información }\end{array}$ & $\begin{array}{l}\text { Convenio } 151 \text { de } 1978 \\
\text { de la OIT, artículo } 6^{\circ} \text {. } \\
\text { Numeral } 2.4 \text { de la } \\
\text { Recomendación } 159 \\
\text { de la CIT. } \\
\text { Numeral } 16 \text { de la Re- } \\
\text { comendación } 143 \text { de } \\
\text { la OIT. }\end{array}$ & $\begin{array}{l}\text { Artículo } 414 \text { numeral } 8^{\circ} \\
\text { del CST. }\end{array}$ & $\begin{array}{l}\text { Convenio } 87 \text { de } 1948 \text { de } \\
\text { la OIT, artículo } 11 . \\
\text { Convenio } 135 \text { de } 1971 \\
\text { de la OIT, artículo } 2 . \\
\text { Numeral } 16 \text { de la Re- } \\
\text { comendación } 143 \text { de } \\
\text { la OIT. }\end{array}$ & $\begin{array}{l}\text { Artículo } \\
373 \text { nume- } \\
\text { ral } 10 \text { CST. } \\
\text { NO ES SUFI- } \\
\text { CIENTE }\end{array}$ \\
\hline
\end{tabular}

\section{CONCLUSIONES}

Las facilidades otorgadas para el desempeño de las funciones sindicales de todos los representantes de los trabajadores, sean estos empleados públicos, trabajadores oficiales o particulares, constituyen el medio idóneo previsto por los instrumentos internacionales, particularmente por la Recomendación 143 de la cIT, para materializar los derechos de asociación y libertad sindical, los cuales también responden a los mandatos de optimización consagrados en el artículo 39 de la Constitución Política de Colombia al otorgarles el fuero sindical y "demás garantías necesarias para el cumplimiento de su gestión" (CP, 1991, art. 39).

Las leyes promulgadas en este sentido se convierten, por excelencia, en el mecanismo más efectivo para lograr el respeto por las sugerencias efectuadas en la Recomendación 143 y reglamentar las garantías para el desempeño de la labor sindical de conformidad con la Constitución Política. No obstante, es importante advertir que dichas facilidades no son taxativas, e igualmente pueden ser aumentadas e incluso mejoradas por acuerdos colectivos, consultas, fallos arbitrales o cualquier otro método que permita determinarlas. 
En este orden de ideas, pese a que las recomendaciones proferidas por la Conferencia Internacional del Trabajo no revisten carácter obligatorio para los Estados Miembros, sí constituyen directrices que deberán ser observadas por las autoridades nacionales para la efectividad de los derechos consagrados en los tratados ratificados por el país, al mismo tiempo que son fuente supletoria de la actividad judicial. Por ende, que la normatividad reconozca y consagre expresamente las recomendaciones de la ciT habla favorablemente del cumplimiento de las normas internacionales del trabajo.

La normatividad colombiana, en lo que atañe al tema objeto de estudio, posee similares connotaciones y alcances, y regula las mismas facilidades tanto para los representantes de las organizaciones de empleados públicos como para los trabajadores particulares. Sin embargo, pese a que existen las mismas prerrogativas para uno y otro tipo de trabajadores, se observa en general deficiencias, toda vez que no se encuentran disposiciones que hagan efectivo el derecho de los representantes sindicales a acceder a los lugares de trabajo de los afiliados, a distribuir información relacionada con la actividad sindical y a disponer de facilidades materiales como espacio para reuniones, material de oficina y lugares para colocar boletines informativos, entre otros. Ha sido la Corte Constitucional quien por vía de interpretación del texto Superior ha Ilegado a reconocer facilidades no establecidas en la normatividad.

A pesar del empeño de Colombia por mejorar y homologar las facilidades para los represen- tantes sindicales del sector público y privado a partir de la reglamentación de los convenios ratificados (específicamente los convenios 151 y 135 de la оाт) y la multiplicidad de normas proferidas en los últimos años, se concluye que estas aún son insuficientes y que se requiere aprovechar la tendencia actual de reglamentación de los convenios internacionales para consagrar expresamente las facilidades de los representantes sindicales. En este sentido sería recomendable la promulgación de una ley que tenga por objetivo llenar los vacíos evidenciados y condensar en un solo texto normativo las facilidades señaladas por la Recomendación 143 para los representantes sindicales.

Ojalá el presente estudio sirva como punto de partida para futuras investigaciones que analicen, mediante estudios de caso en empresas públicas y privadas colombianas, el cumplimiento material de las prerrogativas, garantías y derechos establecidos para el ejercicio de los representantes sindicales en la normatividad nacional e internacional.

\section{Referencias}

Código Sustantivo del Trabajo. Ley 2663 de 1950. Septiembre 9 de 1950 (Colombia).

Concepto 216110 de 2011. [Ministerio de Protección Social]. Permiso sindical y viáticos. Julio 25 de 2011.

Conferencia Internacional del Trabajo. Recomendación sobre los representantes de los trabajadores, 1971 (núm. 143). 
Conferencia Internacional del Trabajo. Recomendación sobre las relaciones de trabajo en la administración pública, 1978 (núm. 159).

Conferencia Internacional del Trabajo. (2013). La negociación colectiva en la administración pública: un camino a seguir. Estudio General relativo a las relaciones laborales y la negociación colectiva en la administración pública.. Conferencia Internacional del Trabajo, $102^{a}$ reunión. Ginebra, Suiza: OIT.

Congreso de la República de Colombia. (Diciembre 28 de 1990). Ley 50 de 1990. Por la cual se introducen reformas al Código Sustantivo del Trabajo y se dictan otras disposiciones.

Congreso de la República de Colombia. (Junio 13 de 2000). Ley 584 de 200. Por la cual se derogan y se modifican algunas disposiciones del Código Sustantivo del Trabajo. DO n. ${ }^{\circ}$ 44.043.

Constituyente. (1991). Constitución Política de Colombia. Bogotá: Editorial Leyer.

Corte Constitucional de Colombia. Sentencia C-377 de 1998 (M. P.: Alejandro Martínez Caballero; julio 27 de 1998).

Corte Constitucional de Colombia. Sentencia C-161 de 2000 (M. P.: Alejandro Martínez Caballero; febrero 23 de 2000).

Corte Constitucional de Colombia. Sentencia C-201 de 2002 (M. P.: Jaime Araújo Rentería; marzo 19 de 2002).
Corte Constitucional de Colombia. Sentencia C-280/07 (M. P.: Humberto Antonio Sierra Porto; abril 18 de 2007).

Corte Constitucional. Sentencia T-619/13 (M. P.: Jorge Iván Palacio Palacio; septiembre 9 de 2013).

Corte Suprema de Justicia. Radicación n. ${ }^{\circ}$ 16788 (M. P.: Germán G. Valdés Sánchez; junio 5 de 2001).

Corte Suprema de Justicia. Sala de Casación Laboral. Radicación n. 36268 (M. P.: Luis Javier Osorio López; marzo 3 de 2010).

Guarnizo, C. (2014). Análisis de la negociación colectiva en el sector público en Colombia: líneas de acción para su implementación eficiente. Bogotá: Organización Internacional del Trabajo.

López, H. (1986). La Misión Chenery: una invitación a pensar en el mediano y largo plazo. Obtenido de Lecturas de Economía: http:// aprendeenlinea.udea.edu.co/revistas/index. php/lecturasdeeconomia/article/view/8007

Organización Internacional del Trabajo. (1948). Convenio (C87) sobre la libertad sindical y la protección del derecho de sindicación. Julio 9, 1948.

Organización Internacional del Trabajo. (1971). Convenio (C135) relativo a la protección y facilidades que deben otorgarse a los representantes de los trabajadores en la empresa. Junio 23, 1971. 
Organización Internacional del Trabajo. (1978). Convenio (C151) sobre la protección del derecho de sindicación y los procedimientos para determinar las condiciones de empleo en la administración pública. Junio 27, 1978.

Organización Internacional del Trabajo. (2006). La libertad sindical: recopilación de decisiones y principios del Comité de Libertad Sindical del Consejo de Administración de la olT [Quinta ed. (revisada)]. Ginebra, Suiza: oIT.

Presidente de la República de Colombia. (18 de octubre de 2013). Decreto 2264 de 2013. Por el cual se reglamentan los artículos 400 del Código Sustantivo del Trabajo y 68 de la Ley 50 de 1990.

Presidente de la República de Colombia. (29 de Diciembre de 2000). Decreto 2813 de 2000.
Por el cual se reglamenta el artículo 13 de la Ley 584 de 2000.

Presidente de la República de Colombia. (5 de febrero de 2014). Decreto 160 de 2014. Por el cual se reglamenta la Ley 411 de 1997 aprobatoria del Convenio 151 de la oІт, en lo relativo a los procedimientos de negociación y solución de controversias con las organizaciones de empleados públicos.

Ramírez, F. (2010). Cartilla guía utilización NIT en decisiones judiciales: Proyecto Promoción de Principios y Derechos Fundamentales en el Trabajo - oІT. Bogotá: oIt.

Villegas Arbeláez. J. (2014). Negociación colectiva y sindicatos de empleados públicos (Sexta ed.). Bogotá: Universidad Externado de Colombia. 